\title{
Iryna Koval
}

\section{WATER DISINFECTION UNDER THE HELIUM INFLUENCE}

The object of research is the process of water disinfection at the influence of gas from bacteria of a particular genus with different amounts per unit volume of water. Due to the annual increase in the amount of pollutants in natural waters, new opportunities to improve microbiological indicators of water quality are being explored. There are many different ways to disinfect it, both physical and chemical. However, no single method has been found to purify aqueous media from microorganisms that would ensure their effective destruction. It is proposed to study the activity of specific microorganisms during the bubbling of inert gas through the aqueous medium. The microorganisms studied were rod-shaped sporogenic cells of Bacillus cereus bacteria type. The test gas was inert helium. The study used continuous gas bubbling throughout the process, which allowed to mix microbial water efficiently and prevent the formation of stagnant zones in the reaction medium. In particular, active gas mixing facilitates its access to each cell. The gas supply rate corresponded to $0.2 \mathrm{~cm}^{3} / \mathrm{s}$, and its flow rate was $0.7 \mathrm{dm}^{3}$ for one hour of bubbling through microbial water. The duration of the entire research process was 7200 s. The constant temperature of the microbial water $(T=288 \pm 1 \mathrm{~K})$ was maintained during the experiment by cooling the glass reactor with running water. An in-depth method of culturing bacterial cells was used. A decrease in the number of microorganisms was observed throughout the helium supply process, despite the different initial amounts in the water. The highest destruction degree of bacillus (77.06 \%) was obtained at the lowest studied concentration in water $\left(\mathrm{NM}_{01}=3.4 \cdot 10^{4} \mathrm{CFU} / \mathrm{cm}^{3}\right)$. This is due to the fact that less microbial load provides better conditions for access of helium to the cell and their effective destruction. The proposed method of water purification allowed to achieve a sufficiently high degree of water disinfection from sporogenic rod-shaped bacteria after the action of helium alone. In particular, it has been experimentally proven that the efficiency of the water disinfection process depends on the concentration of microorganisms per unit volume of water. Due to the treatment of contaminated water with gas, it is possible to obtain high rates of its purification and the application of this method for practical purposes in water treatment technology.

Keywords: water purification, microbiological water pollution, Bacillus cereus bacteria type, microorganisms number, gas bubbling.

\section{Introduction}

The processes of water purification from various microorganisms are still being studied by scientists, because water contains not only pollutants of chemical but also biological pollutants [1-3]. Theoretical sources report the effectiveness of water purification from microbiological contaminants in the bubbling of various gases [4, 5]. Many published studies have focused on studying the effects of oxygen on cells [6-8]. If the oxygen concentration exceeds the level of air saturation, toxic effects on cells are detected [7, 8], which is explained by the accumulation of intracellular reactive oxygen species, which adversely affect cell growth and development. The effect of increased molecular oxygen concentration on the growth and metabolism of eukaryotes and prokaryotes is described in [9]. The argon effect on the Bacillus cereus viability is described in [10], where the active destruction of microorganisms under conditions of argon supply was noted and it was calculated that $k_{d}=(2.3 \pm 0.1) \cdot 10^{-4} \mathrm{~s}^{-1}$. The oxygen effect on aerobic bacteria was studied in [11], where studies have identified and described the processes of accumulation and reduction of microbial counts in the water. At low concentrations of Bacillus bacteria, their active reproduction in an oxygen atmosphere was studied, and at high concentrations, a decrease in the number of cells in water was observed [11]. The influence of hydrogen, argon, oxygen, air and low-intensity ultrasound on the viability of Saccharomyces cerevisiae yeast is described in [12]. However, the effect of helium on the viability of microorganisms in scientific works has not found.

Therefore, it is important to study the viability of microorganisms under the influence of helium, the action of which has not been studied in the processes of water disinfection. Thus, the object of research is the process of water disinfection at the influence of gas from bacteria of a particular genus with different amounts per unit volume 
of water. The aim of research is to study the change of microorganisms number in the aqueous medium in the helium atmosphere.

\section{Methods of research}

A pure culture of Bacillus cereus ATCC 14579 (National Collection of Typical Cultures (bacteria)) was used for the studies. The choice of the studied micro-objects is related to the dominance of these types of bacteria in the different natural waters.

The following scientific methods were used in the study:

- method of deep cultivation of microorganisms;

- method for determining the total number of micro-

organisms, which included the preparation of dilutions and quantification of microorganisms.

Using a microbiological loop, bacterial cells were introduced into freshly prepared distilled water, thus creating model microbial water. Distilled water was pre-disaerated by boiling and further cooling before adding biomass. The method of quantitative determination of bacteria in the water is described in detail in [11]. The volume of prepared microbial test water was $75 \mathrm{~cm}^{3}$, which was poured into a glass reactor. Before pouring microbial water into the reactor, it was sterilized in an oven. The glass reactor is equipped with fittings for thermocouple, gas bubbling and water sampling. The inert gas helium was bubbled into the model water throughout the process at a rate of $0.2 \mathrm{~cm}^{3} / \mathrm{s}$ with a total flow rate of $1.4 \mathrm{dm}^{3}$. The duration of the bubbling process was two hours. Every 30 minutes, water samples were taken to calculate the number of microorganisms $(N M)$. Model waters with different $N M_{0}$ were used for research: $N M_{01}=3.4 \cdot 10^{4} \mathrm{CFU} / \mathrm{cm}^{3}, N M_{02}=4.8 \cdot 10^{4} \mathrm{CFU} / \mathrm{cm}^{3}$ and $N M_{03}=7 \cdot 10^{4} \mathrm{CFU} / \mathrm{cm}^{3}$. The bacterial number per unit volume of water was in the range of $10^{4} \mathrm{CFU} / \mathrm{cm}^{3}$. Process conditions are $T=288 \mathrm{~K}$.

\section{Research results and discussion}

3-day cultures of microorganisms were used for studies, i. e. cells with endospores. It is known from theoretical sources that sporogenic cells are characterized by greater resistance to external factors compared to vegetative.

Initially, the experiments were performed without helium bubbling, i. e. the activity of bacteria in distilled desaerated water was studied. To do this, water samples were taken every 10 minutes for two hours to determine the number of cells. The result of this study showed the invariance of the $N M$ value per unit volume of water.

All calculations of $N M$ values were obtained from the arithmetic mean of three parallel sowings of microbial water samples.

The $N M$ change from the duration of helium bubbling through microbial water is shown in Fig. 1.

Fig. 1 shows the descending curves of the $N M$ ratio from the duration of treatment of microbial water with helium alone. The curves are similar in nature, but differ in the calculated values of the ratio of $N M / N M_{0}$ and the degree of water disinfection.

$N M / N M_{0}$ ratios varies in close range for lower concentrations of microorganisms in water, while for the $N M=7 \cdot 10^{4} \mathrm{CFU} / \mathrm{cm}^{3}$ the value of the $N M / N M_{0}$ after treatment with helium for $7200 \mathrm{~s}$ is almost twice as large (Table 1). This is evidenced by the fact that helium demonstrates higher efficiency of water disinfection at lower numbers of bacillary cells in the aqueous medium. These data confirm the calculated degrees of water disinfection, which are equal to $77.06 \% ; 72.92 \%$ and $47.72 \%$, respectively, for $N M_{01}=3.4 \cdot 10^{4} \mathrm{CFU} / \mathrm{cm}^{3}, N M_{02}=4.8 \cdot 10^{4} \mathrm{CFU} / \mathrm{cm}^{3}$ and $N M_{03}=7 \cdot 10^{4} \mathrm{CFU} / \mathrm{cm}^{3}$. That is, this indicates that the efficiency of destruction of bacterial cells depends on their initial number in the test water.

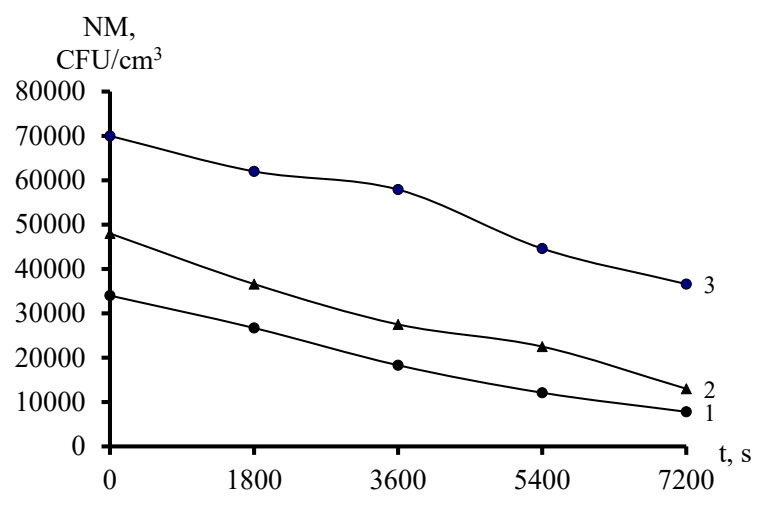

Fig. 1. Change of the $B$. cereus bacteria number of the duration of helium bubbling through the aqueous system. Initial data: $N M_{01}=3.4 \cdot 10^{4} \mathrm{CFU} / \mathrm{cm}^{3}(1), N M_{02}=4.8 \cdot 10^{4} \mathrm{CFU} / \mathrm{cm}^{3}(2)$ and $N M_{03}=7 \cdot 10^{4} \mathrm{CFU} / \mathrm{cm}^{3}(3)$

Table 1

Changing the NM/NMO values after water treatment

\begin{tabular}{|c|c|c|c|}
\hline \multirow{2}{*}{$\begin{array}{c}\text { Duration } \\
\text { of helium } \\
\text { bubbling, } \mathrm{s}\end{array}$} & \multicolumn{3}{|c|}{$\mathrm{NM} / \mathrm{NM}_{0}$ for different initial number of microorganisms } \\
\cline { 2 - 4 } & $3.4 \cdot 10^{4} \mathrm{CFU} / \mathrm{cm}^{3}$ & $4.8 \cdot 10^{4} \mathrm{CFU} / \mathrm{cm}^{3}$ & $7 \cdot 10^{4} \mathrm{CFU} / \mathrm{cm}^{3}$ \\
\hline 1800 & 0.79 & 0.76 & 0.89 \\
\hline 3600 & 0.54 & 0.57 & 0.82 \\
\hline 5400 & 0.36 & 0.47 & 0.64 \\
\hline 7200 & 0.23 & 0.27 & 0.52 \\
\hline
\end{tabular}

Thus, the highest degree of water disinfection $(72.06 \%)$ was achieved with microbial water pollution of $3.4 \cdot 10^{4} \mathrm{CFU} / \mathrm{cm}^{3}$ during bubbling helium alone. In general, the degree of water disinfection at a microbial load of $10^{4} \mathrm{CFU} / \mathrm{cm}^{3}$ is in the range of $47.72 \div 72.06 \%$. This indicates a fairly high efficiency of the use of helium in water treatment processes, given the presence in the water of only resistant microorganisms.

Research should be developed to study the different nature of gases to establish their effective effect on the water purification process, given the fact that this study is limited to the processing of small water volumes.

\section{Conclusions}

According to the results of the study, the effect of bubbled helium through microbial water with different contents of bacillary cells $\left(N M_{01}=3.4 \cdot 10^{4} \mathrm{CFU} / \mathrm{cm}^{3}\right.$, $N M_{02}=4.8 \cdot 10^{4} \mathrm{CFU} / \mathrm{cm}^{3}$ and $N M_{03}=7 \cdot 10^{4} \mathrm{CFU} / \mathrm{cm}^{3}$ ) was shown. The values of the ratio of the initial $N M$ to the current $N M$ after each water sampling are given. The dependence of the change in the number of microorganisms on the duration of treatment is established. The degree of water disinfection for each concentration of microbial cells after the duration of treatment with helium $7200 \mathrm{~s}$ and the efficiency of the gas depending on their 
concentration per unit volume of water were calculated. The proposed method is effective and promising in water treatment technology.

\section{References}

1. Haseena, M., Faheem Malik, M., Javed, A., Arshad, S., Asif, N., Zulfiqar, S., Hanif, J. (2017). Water pollution and human health. Environmental Risk Assessment and Remediation, 1 (3), 16-19. doi: http://doi.org/10.4066/2529-8046.100020

2. Chaudhry, F. N., Malik, M. F. (2017). Factors Affecting Water Pollution: A Review. Journal of Ecosystem E E Ecography, 7 (1). doi: http://doi.org/10.4172/2157-7625.1000225

3. Posthuma, L., Zijp, M. C., De Zwart, D., Van de Meent, D., Globevnik, L., Koprivsek, M. et. al. (2020). Chemical pollution imposes limitations to the ecological status of European surface waters. Scientific Reports, 10 (1), 148-156. doi: http:/ doi.org/10.1038/s41598-020-71537-2

4. Hiragaki, K., Ishimaru, T., Nakanishi, M., Muraki, R., Nieda, M., Yamabe, C. (2015). Generation of ozone foam and its application for disinfection. The European Physical Journal Applied Physics, 71 (2), 20810-20816. doi: http://doi.org/10.1051/ epjap/2015140508

5. Wei, C., Zhang, F., Hu, Y., Feng, C., Wu, H. (2017). Ozonation in water treatment: the generation, basic properties of ozone and its practical application. Reviews in Chemical Engineering, 33 (1), 302-315. doi: http://doi.org/10.1515/revce-2016-0008

6. Ruigrok, M. J. R., Tomar, J., Frijlink, H. W., Melgert, B. N., Hinrichs, W. L. J., Olinga, P. (2019). The effects of oxygen concentration on cell death, anti-oxidant transcription, acute inflammation, and cell proliferation in precision-cut lung slices.
Scientific Reports, 9 (1), 16239-16252. doi: http://doi.org/ 10.1038/s41598-019-52813-2

7. Korshunov, S., Imlay, J. A. (2006). Detection and Quantification of Superoxide Formed within the Periplasm of Escherichia coli. Journal of Bacteriology, 188 (17), 6326-6334. doi: http:// doi.org/10.1128/jb.00554-06

8. Imlay, J. A. (2008). Cellular Defenses against Superoxide and Hydrogen Peroxide. Annual Reviez of Biochemistry, 77 (1), 755-776. doi: http://doi.org/10.1146/annurev.biochem.77.061606.161055

9. Baez, A., Shiloach, J. (2014). Effect of elevated oxygen concentration on bacteria, yeasts, and cells propagated for production of biological compounds. Microbial Cell Factories, 13 (1), 181-198. doi: http://doi.org/10.1186/s12934-014-0181-5

10. Koval, I. Z. (2020). Viability of sporogenic bacteria in an inert gas atmosphere. Scientific Herald of Chernivtsy University. Biology, 12 (1), 8-13.

11. Koval, I. (2020). Influence of Aerobic Bacteria Concentration on the Process of its Survival in the Presence of Oxygen. Visnyk of $V$. N. Karazin Kharkiv National University Series «Ecology», 23, 118-123. doi: http://doi.org/10.26565/ 1992-4259-2020-23-10

12. Dai, C., Xiong, F., He, R., Zhang, W., Ma, H. (2017). Effects of low-intensity ultrasound on the growth, cell membrane permeability and ethanol tolerance of Saccharomyces cerevisiae. Ultrasonics Sonochemistry, 36, 191-197. doi: http:// doi.org/10.1016/j.ultsonch.2016.11.035

Iryna Koval, PhD, Department of Physical, Analytical and General Chemistry, Lviv Polytechnic National University, Lviv, Ukraine, e-mail: irynazk@gmail.com, ORCID: https://orcid.org/0000-00018154-4154 